\title{
Ensayo sobre algunas implicaciones de la política exterior America First en el multilateralismo
}

\author{
Essay on some implications of the America First foreign \\ policy on multilateralism
}

Essai sur certaines implications de la politique etrangere America First sur le multilateralisme

\section{María Concepción Juárez Castro* Laura Elena Pardo Contreras**}

\begin{abstract}
SUMARIO: I. Introducción. II. Estados Unidos de América en la arquitectura y defensa del sistema multilateral. III. La llegada al poder de Donald Trump: el aislacionismo renovado y los desafíos al orden internacional. IV. Consideraciones finales. V. Bibliografía.
\end{abstract}

* Licenciada en Derecho por la Facultad de Derecho de la Universidad Nacional Autónoma de México (UNAM) y especialista en derecho internacional público por la División de Estudios de Posgrado de la misma facultad.

** Licenciada en Relaciones Internacionales por el Instituto Tecnológico Autónomo de México (ITAM) y maestra en Derecho Internacional por la Universidad de Sussex. Es asociada del Consejo Mexicano de Asuntos Internacionales.

Artículo recibido el 15 de octubre de 2018 Aprobado para publicación el 3 de octubre de 2019 
RESUMEN: Estados Unidos de América fue el principal impulsor del multilateralismo y del desarrollo del derecho internacional durante el siglo XX, el ejemplo por excelencia fue la creación del Sistema de las Naciones Unidas. Sin embargo, la llegada de Donald Trump a la presidencia ha revelado algunos desafíos para el ámbito multilateral. Si bien, las acciones recientes de política exterior de su administración ponen a prueba el sistema de gobernanza global, se ha demostrado que la acción multilateral es todavía la mejor manera de enfrentar los grandes problemas de la humanidad. Frente a esos desafíos, diversos temas de la agenda internacional y normas jurídicas deberán demostrar su resiliencia para enfrentar el alejamiento de Estados Unidos de América al sistema del que fue arquitecto.

Palabras clave: multilateralismo, política exterior, gobernanza global.

ABSTRACT: The United States of America was the main promoter of multilateralism and the development of international law in the 20th century, the example par excellence was the establishment of the United Nations System. However, Donald Trump's arrival to the presidency has revealed some challenges for the multilateral sphere in key aspects. Although recent foreign policy actions of his administration have tested the global governance system, it has been demonstrated that multilateral action is still the best way to face the greatest problems of humanity. To address these challenges, various international agenda topics and norms might prove their resiliency to face the distance of the USA towards the system it was the architect of. Key words: multilateralism, foreign policy, global governance.

RÉSUMÉ: Les États-Unis d'Amérique ont été le principal moteur du multilatéralisme et du développement du droit international pendant le XXème siècle, l'exemple par excellence a été la création du System des Nations Unies. Cependant, l'arrivée de Donald Trump à la présidence a révélée quelques défis dans l'espace multilatérale en domaines clés. Alors que les actions dans la politique étrangère de son administration mettent à l'épreuve la gouvernance globale, on constate que l'action multilatérale reste le meilleur moyen de traiter les grands problèmes de l'humanité. Plusieurs questions à l'ordre du jour international et des normes resteront résilientes pour faire face à la distance des États Unis au système dont ils ont été l'architecte.

Mots-clés: multilatéralisme, politique étrangère, gouvernance globale. 


\section{INTRODUCCIÓN}

Como consecuencia de la Segunda Guerra Mundial diversos países sufrieron transformaciones políticas, económicas, sociales y geográficas, incluso el mundo tuvo que cuestionar si las normas jurídicas, que regulaban las relaciones entre Estados, eran lo suficientemente sólidas y efectivas para mantener la paz y la seguridad internacionales. De esa manera, con el reconocimiento de nuevos sujetos de derecho - las organizaciones internacionales, los individuos y los beligerantes_- la diversificación y especialización de temas en la agenda mundial y la creación de foros de discusión y deliberación, se desvaneció la preponderancia de las acciones unilaterales y bilaterales de los países que caracterizaron la primera mitad del siglo XX.

Al concluir el conflicto bélico, los Estados que habían participado activamente en él, así como aquellos que habían sido utilizados como corredores para transportar insumos a los combatientes o para el desplazamiento humano, y los territorios que se mantuvieron neutrales, apoyaron la iniciativa estadounidense y británica de constituir una organización mundial que superara las deficiencias de la Liga de las Naciones. ${ }^{1}$ Específicamente, destacó el impulso de Estados Unidos de América (EE UU) en el diseño de la nueva entidad: la denominación propuesta por el presidente Franklin D. Roosevelt en la Declaración de las Naciones Unidas del 10. de enero de $1942,^{2}$ y los planteamientos de estructura y funcionamiento que se plasmaron en la Carta del Atlántico (1941), en las Declaraciones de Moscú y Teherán (1943), en las Conferencias de Dumbarton Oaks y Yalta (1944 y 1945, respectivamente), y por supuesto, en la Conferencia de San Francisco (1945). Así, el 24 de octubre de 1945 surgió la Organización de las Naciones Unidas (ONU), organismo internacional que puso en relieve a nuevos actores y el papel que éstos desempeñan en la comunidad mundial, así como en el desarrollo de las normas que integran el cuerpo jurídico internacional. Con el nacimiento de la ONU, EE UU se convirtió en un país con un papel preponderante en el contexto mundial dada su influencia

Cfr. Carrillo Suárez, Agustín Eduardo, "Los organismos internacionales", Curso de actualización de profesores de derecho internacional privado, Cuadernos de trabajo del Seminario de Derecho Internacional, México, UNAM, Facultad de Derecho, 2009, p. 54. Disponible en: ttps: / / archivos.juridicas. unam.mx/www/bjv/libros/9/4056/12.pdf.

2 Disponible en: http://www.un.org/es/sections/history-united-nations-charter/1942-declaration-united-nations/index.html. 
y hegemonía en las decisiones que se adoptaban, no solo como uno de los 51 Estados miembros fundadores, sino como uno de los cinco miembros permanentes del Consejo de Seguridad (CSONU). De este modo, se convirtió en arquitecto del sistema multilateral, artífice de las normas jurídicas internacionales, e influencia en el diseño de la política exterior de varias latitudes. ${ }^{3}$

\title{
II. ESTADOS UNIDOS DE AMÉRICA EN LA ARQUITECTURA Y DEFENSA DEL SISTEMA MULTILATERAL
}

\begin{abstract}
Convencidos que una victoria absoluta sobre sus enemigos es esencial para defender la vida, la libertad, la independencia y la libertad de religión, y preservar los derechos humanos y la justicia tanto en sus propias tierras, así como en otras, y que ahora están comprometidos en la lucha común en contra de las fuerzas bárbaras e inhumanas que tratan de subyugar al mundo...
\end{abstract}

Declaración de las Naciones Unidas, 1o. de enero de 1942

\section{La razón de ser del multilateralismo}

Por décadas, la ONU y los organismos internacionales creados posteriormente - algunos establecidos de manera anterior a 1945, como la Unión Postal Universal - han abanderado los problemas que atañen a la comunidad internacional en general. Por ese motivo, los Estados - como sujetos tradicionales del derecho internacional-se unieron, coordinaron y cooperaron entre sí para enfrentar los retos del contexto mundial a través de foros, agrupaciones y posicionamientos que les eran comunes, ${ }^{4}$ a esta figura se le conoce como multilateralismo.

3 Cfr. Corell, Hans, "The Mandate of the United Nations Security Council in a Changing World", en Ebbesson, Jonas et al. (eds.), International Law and Changing Perceptions of Security: Liber Amicorum Said Mahmoudi, Leiden-Boston, Brill-Martinus Nijhoff Publishers, 2014, p. 41. Disponible en: http: / / www.havc.se/res/SelectedMaterial/20142224ilperceptionsofsecurity.pdf.

4 Para Robert O. Keohane y Lisa L. Martin, "las instituciones internacionales pueden proveer [a los Estados] de información, reducir los costos de transacción y hacer que los compromisos sean más creíbles, establecer puntos focales para la coordinación y facilitar la operación de reciprocidad [entre los actores de la comunidad internacional]" (la traducción es propia). Keohane, Robert O. y Martin, Lisa L., "The Promise of Institutionalist Theory", International Security, Massachusetts, vol. 20, núm. 1, 1995, p. 42. Disponible en: https:// 
El multilateralismo es definido como "una forma institucional que coordina el comportamiento entre tres o más Estados sobre las bases de principios generalizados de conducta" (la traducción es propia). Esto significa que el desarrollo del derecho y de las instituciones internacionales difuminaron los límites teóricos de la soberanía, ${ }^{6}$ y los Estados aceptaron la necesidad de participar con otros actores —organismos internacionales, individuos, organizaciones no gubernamentales, entidades federativas, empresas transnacionales, comunidades académicas y científicas, etcétera-, para trabajar conjuntamente en temas y enfoques que anteriormente se consideraban exclusivos del ámbito interno o privado. Tal como lo señala el embajador Miguel Ruiz Cabañas, "el multilateralismo es una expresión de la diplomacia y de la política internacional, cuyo objetivo es ofrecer soluciones comunes a problemas comunes". ${ }^{7}$

Existe la mayoritaria percepción de que determinados asuntos constituyen desafíos para la comunidad internacional en su conjunto, de manera tal que no pueden ser resueltos unilateral o exclusivamente con acciones a nivel interno, sino que necesitan un enfoque común y coordinado, que solo puede alcanzarse a través de la negociación y la voluntad política común de los gobiernos expresada a nivel multilateral. ${ }^{8}$

www.uio.no/studier/emner/hf/iakh/HIS4421/h11/undervisningsmateriale/HIS4421_KeohaneMartinInstitutionalism.pdf.

5 Ruggie, John Gerard, "Multilateralism: The Anatomy of an Institution”, International Organization, Massachusetts, vol. 46, núm. 3, 1992, p. 568. Disponible en: https://scholar. harvard.edu/files/john-ruggie/files/multilateralism.pdf.

6 Cfr. Tardif, Eric, "Metamorfosis de la soberanía: elementos para una redefinición del concepto a la luz del derecho internacional contemporáneo”, Anuario de Derecho Constitucional Latinoamericano, Montevideo, año XVI, enero-diciembre de 2010, pp. 307-322. Disponible en: https: //revistas-colaboracion.juridicas.unam. $m x /$ index.php/anuario-derecho-constitucional/article/view/3929/3452.

7 Ruiz Cabañas Izquierdo, Miguel y Rivera Chávez, María Paulina, "En defensa del multilateralismo", Revista Mexicana de Política Exterior, México, núm. 110, mayo-agosto de 2017, p. 11. Disponible en: https://revistadigital.sre.gob.mx/images/stories/numeros/n110/ruizcabanasrivera.pdf.

8 Keohane, Robert O. y Nye, Joseph S., Poder e interdependencia. La política mundial en transición, Buenos Aires, Grupo Editor Latinoamericano, 1977, citado en Lagos, Enrique, "Algunas tendencias del derecho internacional a principios del siglo XXI", Anuario Mexicano de Derecho Internacional, México, vol. V, 2005, p. 315. Disponible en: https://revistas.juridicas. unam.mx/index.php/derecho-internacional/article/view/122/184\#N11. 
La maquinaria del Sistema de Naciones Unidas —incluyendo los órganos principales, sus fondos, agencias especializadas y programas - ha demostrado que el multilateralismo ha sido, en ciertos temas (por ejemplo, el mantenimiento de la paz y seguridad internacionales - incluyendo el despliegue de las operaciones de mantenimiento de la paz-, el desarrollo sostenible, el desarme nuclear y en algunos casos, el desarme en general; así como la promoción y protección de los derechos humanos) un modelo propicio para la atención de los desafíos de la comunidad internacional. A través de los foros aumenta la membresía, los países interactúan entre sí —independientemente de su localización geográfica o de su desarrollo económiCo- - participan en procesos de negociación en los que comparten y debaten perspectivas, y son representados en las mesas de discusión.

A pesar de la aceptación del multilateralismo, existen ejemplos exitosos de integración regional en el mundo como la Unión Europea, los cuales no minimizan ni excluyen el progreso del multilateralismo, por el contrario, los bloques regionales resuelven desafíos que son comunes a Estados que mantienen cercanía geográfica, identidad política, económica o cultural, y así, el regionalismo se enfoca en problemas específicos. Es decir, la integración regional se centra en las acciones de un número indefinido, pero limitado de países que buscan la coordinación, convergencia y ayuda mutua para resolver problemas, fortalecer instituciones o mejorar las condiciones de un territorio definido; mientras que el multilateralismo se encarga de atender aquellos retos que ningún Estado o bloque de países puede resolver por sí solos, sino que se requiere de la cooperación colectiva para encontrar soluciones viables a problemas comunes que atañen al mundo entero. ${ }^{9}$

De esa manera, el multilateralismo ha fortalecido las relaciones entre los sujetos de derecho y ha conducido a la formación de normas jurídicas internacionales que permiten alcanzar fines y objetivos comunes; al mismo tiempo, propicia la formulación de las políticas exterior e interior de los Estados, respaldadas y alentadas por los acontecimientos y desarrollos multilaterales.

Las decisiones que los gobiernos adoptan para conducir la política exterior e interior se encuentran interrelacionadas y mantienen un alto

9 Al respecto, se sugiere consultar a Forero Rodríguez, Mario A., "Integración y multilateralismo en el marco de las relaciones económicas internacionales”, Revista Análisis Internacional, núm. 3, 2011, pp. 54 y 55. Disponible en: https: //revistas.utadeo.edu.co/index.php/RAI/ article/download/72/75. 
grado de influencia entre sí, éstas no operan en el vacío. Gabriela Rodríguez señala que la política exterior está sustentada en una serie de principios que derivan de los procesos históricos particulares de cada Estado, ${ }^{10}$ y la explica de la siguiente manera:

La política exterior puede definirse como las directrices y estrategias delineadas por cada Estado para conducir sus relaciones con otros Estados y actores internacionales, con intereses claramente establecidos para cumplir objetivos nacionales específicos en el plano internacional. ${ }^{11}$

Así, como consecuencia de distintas decisiones que se han adoptado en los periodos presidenciales en EE UU, la política exterior de ese país se ha ido transformando. Cada una de las acciones internas ha tenido repercusiones en el exterior, y dado el papel hegemónico de ese país en el escenario mundial, influyen directamente en la formación de las normas jurídicas y en la evolución de las relaciones internacionales.

Múltiples factores internos y externos favorecen la solidez de los Estados, de sus instituciones y de su pueblo, a la par inclinan la balanza dentro de los foros internacionales cuando hay que tomar decisiones y adoptar posicionamientos.

2. Prioridades de la política exterior de Barack Obama: el acercamiento y la reconciliación con el mundo

Barack Obama, de formación internacionalista, criticó la visión que consideraba que "el derecho internacional era una invasión a la soberanía estadounidense y una restricción a su capacidad para imponer su voluntad en todo el mundo" (la traducción es propia). ${ }^{12}$ Contrario a esto, la política exterior del presidente Obama se basó en privilegiar la prevalencia de intereses mutuos con distintos países. Así, los ejes de la relación con el mundo

10 Rodríguez Huerta, Gabriela, México en el mundo. Constitución y política exterior, México, Fondo de Cultura Económica, 2017, p. 35.

11 Ibidem, p. 36.

12 Goldsmith, Jack, "The Contributions of the Obama Administration to the Practice and Theory of International Law", Harvard International Law Journal, Massachusetts, vol. 57, núm. 2, 2016, p. 455. Disponible en: https://harvardilj.org/wp-content/uploads/sites/15/Goldsmith_HILJ-Online-Version_23-June-2016_Final.pdf. 
fueron: el retiro de las tropas de Iraq, la cuestión de Afganistán y el relanzamiento de las relaciones con amigos y enemigos. ${ }^{13}$ Por ello, los derechos humanos y la democracia sí constituyeron un eje de su política exterior, pero no el centro. Esta premisa le permitió renovar relaciones con Rusia, Irán, China, Sudán y con las instituciones multilaterales, por mencionar algunas. ${ }^{14}$

Durante su campaña, Obama criticó a la administración Bush por el débil cumplimiento de los compromisos de EE UU en materia de derecho internacional sobre el uso de la fuerza y los derechos humanos. ${ }^{15}$

[S]olo podemos entender la promesa de fundación de esta institución — reemplazar los estragos de la guerra con la cooperación - si naciones poderosas como la mía aceptan restricciones. A veces soy criticado en mi propio país por profesar una creencia en las normas internacionales y las instituciones multilaterales. Pero estoy convencido de que a la larga, renunciar un poco a la libertad de acción, sin renunciar a nuestra capacidad de protegernos o de perseguir nuestros intereses centrales, sino aferrándonos a las reglas internacionales a largo plazo, mejora nuestra seguridad.Y creo que eso no es solo cierto para nosotros (la traducción es propia). ${ }^{16}$

De esa manera, la misión encomendada al Departamento de Estado durante la administración Obama fue formar y mantener un mundo pacífico, próspero, justo y democrático, y fomentar las condiciones para la estabilidad y el progreso en beneficio del pueblo estadounidense y de la gente de todo el mundo. ${ }^{17}$ Por ello, se puede afirmar que EE UU tuvo una agenda global destinada a cambiar su relación con el mundo. Dentro del acercamiento con amigos y antiguos enemigos se incluyeron aspectos como la

13 Packer, George, "Rights and Wrongs", The New Yorker, 17 de mayo de 2010. Disponible en: https: / /www.newyorker.com/magazine/2010/05/17/rights-and-wrongs.

14 Unger, David, “The Foreign Policy Legacy of Barack Obama”, The International Spectator, Bologna, vol. 51, núm. 4, 2016, p. 5. Disponible en: http://www.iai.it/sites/default/files/ unger.pdf.

15 Goldsmith, Jack, op. cit., p. 455.

16 Reilly, Katie, "Read Barack Obama's Final Speech to the United Nations as President", TIME, 20 de septiembre de 2016. Disponible en: http://time.com/4501910/president-obamaunited-nations-speech-transcript/.

17 Delclaración de misión del Departamento de Estado de Estados Unidos de América 2009-2017. Disponible en: https://2009-2017.state.gov/s/d/rm/index.htm\#mission. 
normalización de las relaciones con Cuba, el apoyo al Acuerdo Nuclear con Irán, la campaña aérea de la OTAN (Organización del Tratado del Atlántico Norte) sobre Libia bajo el principio de "Responsabilidad de proteger", la defensa a la Primavera Árabe; y logros como la muerte de Osama Bin Laden y el retiro de tropas de Iraq. ${ }^{18}$

Otro de sus principales objetivos fue aliviar las tensiones entre los países musulmanes y EE UU, especialmente en cuanto a la promoción de la democracia como motivación para tomar acciones, por ejemplo, la invasión de Iraq. Así, reconoció en su discurso "Un nuevo comienzo", pronunciado en El Cairo el 4 de junio de 2009, que ningún sistema de gobierno debe ser impuesto por otro, ${ }^{19}$ lo que también ejemplifica su política exterior de privilegiar las coincidencias con sus socios. De lo más comentado - y reprochado - fue la inacción en Siria, ${ }^{20}$ pues aun cuando había declarado que no intervendría a menos que se utilizaran armas químicas, dejó la decisión a consideración del Congreso cuando se comprobó su uso, y éste decidió no intervenir. ${ }^{21}$

En los dos periodos del presidente Obama, EE UU tomó una serie de decisiones que contribuyeron a incrementar la confianza en las normas jurídicas y en las relaciones internacionales, verbigracia, la lucha contra el terrorismo, el régimen de no proliferación de armas nucleares - a pesar de ser uno de los opositores a la adopción del Tratado sobre la Prohibición de Armas Nucleares - ${ }^{22}$ la solución de la controversia nuclear con Irán por la vía diplomática (a través del Joint Comprehensive Plan of Action, JCPOA, por su sigla en inglés, o Acuerdo Nuclear de Irán), la apertura de relaciones con Cuba, el apoyo para alcanzar el fin de la guerra entre el gobierno colombiano y las Fuerzas Armadas Revolucionarias de Colombia (FARC), las po-

18 Packer, George, "Witnessing the Obama Presidency, from Start to Finish", The New Yorker, 18 de junio de 2018. Disponible en: https://www.newyorker.com/magazine/2018/06/18/ witnessing-the-obama-presidency-from-start-to-finish.

19 Packer, George, "Rights...", cit.

20 Packer, George, "Witnessing...", cit.

21 Murdock, Sebastian, "Majority of Republicans Said «No» When Obama Wanted to Launch a Strike on Syria”, Huffpost, 4 de julio de 2017. Disponible en: https: / / www.huffpost. com/entry/republicans-strike-syria-trump_n_58e6f71de4b051b9a9da355d.

22 Cfr. Rühle, Michael, “The Nuclear Weapons Ban Treaty: Reasons for Scepticism”, NATO Review, 19 de mayo de 2017. Disponible en: https://www.nato.int/docu/review/2017/alsoin-2017/nuclear-weapons-ban-treaty-scepticism-abolition/en/index.htm. 
líticas DACA (Deferred Action for Childhood Arrivals) y DAPA (Deferred Action for Parents of American and Lawful Permanent Residents) para la población migrante, entre otras cuestiones. ${ }^{23}$

Sin embargo, el presidente Obama también fue cuestionado duramente por no haber cumplido algunas promesas de campaña que incluían el retiro integral de las tropas de ultramar, la pacificación de Iraq, Libia y/o Siria, el cierre de la prisión de Guantánamo, las protestas de la Primavera Árabe, los cuestionamientos sobre el uso de drones en los conflictos armados y su marco jurídico, la debilidad del Acuerdo de Asociación Transpacífico (TPP [TransPacific Partnership]), las filtraciones de información y espionaje, la anexión de Crimea y Sebastopol a la Federación de Rusia, la crisis en Venezuela, la solución del conflicto palestino-israelí, y la reforma migratoria integral. ${ }^{24}$

De forma destacada, el 31 de marzo de 2009, la Secretaria de Estado, Hillary Clinton, y la Representante Permanente de EE UU ante la ONU, Susan Rice, anunciaron que su país buscaría un escaño en el Consejo de Derechos Humanos de la ONU para convertirlo en un cuerpo efectivo, y promover los derechos humanos. ${ }^{25}$ En mayo de 2009, EE UU fue elegido para tomar un asiento en el Consejo con el apoyo de 167 Estados miembros de la Asamblea General de la ONU (AGONU), ${ }^{26}$ a lo que Rice manifestó:

Nos presentamos ante el Consejo de Derechos Humanos porque esta administración y, de hecho, el pueblo estadounidense, están profundamente comprometidos con la defensa y el respeto de los derechos humanos de cada persona. Si bien reconocemos que el Consejo de Derechos Humanos ha sido un organismo defectuoso que no ha estado a la altura de su potencial, esperamos trabajar desde adentro con una amplia unidad transversal de Estados miembros para fortalecer y reformar el

23 Faus, Joan, "La doctrina exterior de Obama, en 11 claves", E1 País, 15 de marzo de 2016. Disponible en: https://elpais.com/internacional/2016/03/14/estados_unidos/1457971957_819516.html.

24 Pereda, Cristina F., "Examen a las grandes promesas de Obama”, E1 País, 18 de agosto de 2016. Disponible en: https://elpais.com/internacional/2016/08/17/estados_unidos/1471396016_268432.html.

25 Groves, Steven y Schaefer, Brett, “The U.N. Human Rights Council: No Better for Obama's Engagement”, The Heritage Foundation, 2009. Disponible en: https://www.heritage. org/report/the-un-human-rights-council-no-better-obamas-engagement.

26 Los resultados de la votación en la Asamblea General de la Organización de las Naciones Unidas del 12 de mayo de 2009 están disponibles en: http://www.un.org/en/ga/63/elections / hrc_elections.shtml. 
DOI: http://dx.doi.org/10.22201/iij_24487872e_2020.20.14491

Consejo de Derechos Humanos y permitirle estar a la altura de la visión que se creó cuando se creó (la traducción es propia). ${ }^{27}$

Durante su participación en el Consejo, EE UU fue considerado una las delegaciones más activas al emitir pronunciamientos y condenar la situación de los derechos humanos en países como Costa de Marfil, Libia, Guinea y Haití. ${ }^{28}$ A pesar de eso, el gobierno estadounidense fue duramente criticado tras someterse al Examen Periódico Universal, en 2015. El resultado de esa evaluación fueron 343 recomendaciones en materia de derechos humanos que versaron sobre el uso desproporcionado de la fuerza policial contra la población civil, la discriminación racial y el uso de drones contra civiles. Asimismo, se le recomendó ratificar la Convención sobre los Derechos del Niño, y ser parte de la Convención de la Eliminación de Todas las Formas de Discriminación Contra la Mujer y la de los Derechos de las Personas con Discapacidad. ${ }^{29}$

También, el presidente Obama defendió el valor de la Organización Mundial del Comercio (OMC) como foro multilateral, destacó la importancia del intercambio de bienes, servicios e inversiones en todo el mundo, y a la Organización como el espacio guardián y generador de las normas que rigen al sistema de comercio internacional. En diciembre de 2016 durante el 13o. examen de políticas comerciales, el Representante Permanente de EE UU ante la OMC, Michael Punke, señaló lo siguiente:

Nos complace estar observando un consenso cada vez más amplio de que se necesita un multilateralismo pragmático, un multilateralismo que reconozca que el mundo ha cambiado drásticamente en las últimas dos décadas, que algunos paí-

27 Comentarios de la Representante Permanente de los Estados Unidos, Susan E. Rice, después de las elecciones del Consejo de derechos Humanos ante la Asamblea General, citado en Groves, Steven y Schaefer, Brett, op. cit.

28 Oficina de Asuntos de Organismos Internacionales del Departamento de Estado de EE UU, "Revitalizing the United Nations and Multilateral Cooperation: The Obama Administration's Progress", comentarios, 1o. de febrero de 2011. Disponible en: https: / /2009-2017.state.gov/p/io/rm/2011/155854.htm.

29 Cfr. Consejo de Derechos Humanos de la Asamblea General de la Organización de las Naciones Unidas, "Informe del Grupo de Trabajo sobre el Examen Periódico Universal: Estados Unidos de América”, 30o. periodo de sesiones (A/HRC/30/12), 20 de julio de 2015. Disponible en: https://www.ohchr.org/EN/HRBodies/HRC/RegularSessions/Session30/ Documents/A_HRC_30_12_SPA.docx. 
ses en desarrollo se han convertido en mercados emergentes competitivos a nivel mundial, liderando economías, y que ese papel, en la economía global, conlleva más responsabilidad (la traducción es propia). ${ }^{30}$

En concordancia con el discurso proclamado, en diciembre de 2016, el gobierno de Obama incoó un procedimiento contra China — su principal competidor mundial en el ámbito comercial — ante el órgano de solución de diferencias de la OMC. La disputa versó sobre diversas medidas de ayuda interna — subsidios - que el país asiático otorgó a los productores agropecuarios de trigo, arroz indica, arroz japónica y maíz. Así, EE UU consideró que la medida era incompatible con diversos acuerdos previamente celebrados y que limitaban de manera desleal el acceso de sus cereales al mercado chino. ${ }^{31}$

Incluso Obama promovió la decisión de formar parte del Acuerdo de París sobre cambio climático, el cual entró en vigor cuatro días antes de tener lugar la elección presidencial de EE UU Unos meses más tarde, la política exterior de ese país cambiaría radicalmente.

\section{LA LLEGADA AL PODER DE DONALDTRUMP: EL AISLACIONISMO RENOVADO Y LOS DESAFÍOS AL ORDEN INTERNACIONAL}

\section{La politica exterior de Donald Trump: America First}

El 20 de enero de 2017, Donald Trump se convirtió en el cuadragésimo quinto presidente de EE UU después de un inesperado resultado en la contienda electoral. Durante su campaña declaró que, de llegar a convertirse en mandatario de ese país adoptaría diversas acciones que cambiarían las decisiones que caracterizaron a Barack Obama, incluyendo algunas en materia de política exterior. ${ }^{32}$

30 Declaración del embajador de Estados Unidos, Michael Punke, en el 13o. Examen de Políticas Comerciales de la OMC, 19 de diciembre de 2016. Disponible en: https: / / ustr.gov / aboutus/policy-offices / press-office/speechestranscripts/2016/december/Statement-US-13-WTO-TPR-USA.

31 Cfr. Organización Mundial del Comercio, Solución de Diferencias DS511: China-Ayuda interna para los productores agropecuarios. Disponible en: https://www.wto.org/spanish/tratop_s/ dispu_s/cases_s/ds511_s.htm.

32 Borger, Julian, "In Pledging to Put «America First», Trump Holds the World at his Mercy”, The Guardian, 20 de enero de 2017. Disponible en: https://www.theguardian.com/ world/2017/jan/20/trump-inauguration-america-first-foreign-policy. 
Con la llegada de Trump a la presidencia, la relación de EE UU con el mundo cambió. Desde su campaña abogó por una política exterior muy diferente a la de su antecesor con promesas como la construcción de un muro en la frontera con México, el traslado de la embajada estadounidense en Israel hacia Jerusalén —incluso anunció el cierre de la Oficina de Representación de la Organización para la Liberación de Palestina en Washington, $\mathrm{DC}$ - , la renegociación del JCPOA, el retiro de las bases militares estadounidenses en Japón y Corea del Sur, la denuncia del Acuerdo de París sobre cambio climático, la reconsideración de su membresía en la OTAN, la renegociación del Tratado de Libre Comercio de América del Norte (TLCAN), la mejora de las relaciones con Rusia, el término del conflicto en Siria y el bombardeo al Estado Islámico, entre otras. ${ }^{33}$

Trump dejó entrever tres creencias: su postura en contra del comercio y de las alianzas, y estar a favor del liderazgo fuerte. ${ }^{34}$ También fue claro que el fortalecimiento del régimen de gobernanza global no era su objetivo y desde el inicio de su presidencia — a través de la firma de órdenes ejecutivas como "La seguridad fronteriza y aplicación de mejoras migratorias", o la "Orden Ejecutiva de Independencia Energética”—— ${ }^{35}$ comenzó a menguar el liderazgo de EE UU a nivel mundial. ${ }^{36}$

33 Timm, Jane C., “The 141 Stances Donald Trump Took During his White House Bid”, NBC News, 28 de noviembre de 2016. Disponible en: https: / www.nbcnews.com/politics/2016election/full-list-donald-trump-s-rapidly-changing-policy-positions-n547801.

34 Saunders, Elizabeth N., "Is Trump a Normal Foreign-Policy President? What We Know After One Year”, Foreign Affairs, 18 de enero de 2018. Disponible en: https: / /www.foreignaffairs.com/articles/united-states/2018-01-18/trump-normal-foreign-policy-president.

35 1) Minimizing the Economic Burden of the Patient Protection and Affordable Care Act; 2) Expediting Environmental Reviews and Approvals for High Priority Infrastructure Projects; 3) Border Security and Immigration Enforcement Improvements; 4) Enhancing Public Safety in the Interior of the United States; 5) Protecting the Nation form Foreign Terrorist Entry into de United States; 6) Ethics Commitments by Executive Branch Appointees; 7) Reducing Regulation and Controlling Regulatory Costs; 8) Core Principles for Regulating the United States Financial System; 9) Enforcing Federal Law With Respect to Transnational Criminal Organizations and Preventing International Trafficking; 10) PreventingViolence Against Federal, State, Tribal, and Local Law Enforcement Officers; 11) Providing an Order of Succession Within the Department of Justice.

También véanse las órdenes ejecutivas de Donald Trump en 2017. Disponibles en: https: / / www.federalregister.gov/presidential-documents/executive-orders/donald-trump/2017.

36 Boon, Kristen, "President Trump and the Future of Multilateralism", Emory International Law Review, Atlanta, vol. 31, 2017, p. 1076. Disponible en: http://law.emory.edu/eilr/recentdevelopments / volume-31 / essays / president-trump-future-multilateralism.html. 
El inicio del periodo presidencial de Trump se dio en un contexto mundial de desafíos al orden liberal existente, de incertidumbre, de bajo crecimiento económico, de intensificación en las voces proteccionistas con fenómenos como el Brexit, de auge de las derechas en Europa, de crisis de refugiados y humanitarias, de la amenaza nuclear de Corea del Norte, de terrorismo y extremismo violento, de políticas migratorias cada vez más restrictivas, así como de conflictos y crisis latentes en Venezuela, Yemen, Siria o Ucrania. Contrario a su antecesor, el Departamento de Estado transformó su mandato para encargarse de liderar la política exterior de EE UU, a través de la diplomacia, la defensa y la asistencia, al promover los intereses del pueblo estadounidense, su seguridad y prosperidad económica. ${ }^{37}$

A raíz del discurso nacionalista y proteccionista adoptado por Trump y su famoso lema America First, las prioridades de la agenda multilateral se han revalorizado y el orden internacional ha atestiguado cambios. Incluso problemas globales que se consideraban superados o que se encontraban en un impasse (estancamiento), han vuelto a la mesa del debate. Pareciera que el punto de inicio de la política exterior de Donald Trump es el enojo y el argumento de que los aliados de EE UU se aprovechan de él; ${ }^{38}$ además, su desdén por las acciones e instituciones multilaterales se ha hecho patente desde sus primeros días en el poder. Si bien, este país tiene membresía originaria en las organizaciones internacionales más importantes, como la propia ONU, e incluso fue arquitecto del orden y régimen de gobernanza globales que hoy conocemos, ha cumplido sus promesas de campaña y ha dado la espalda a importantes instrumentos y entidades multilaterales.

\section{El desdén hacia los instrumentos e instituciones multilaterales}

Para ejemplificar la actitud del nuevo gobierno de EE UU hacia los compromisos negociados y adquiridos, se expondrán los casos de los acuerdos de París y Nuclear de Irán, respectivamente, ya que se trata de asuntos que afectan a todo el mundo y que constituyen triunfos e innovaciones del multilateralismo. Asimismo, se analizará el efecto en las instituciones de la

37 Más información del Departamento de Estado de Estados Unidos de América disponible en: https: / / www.state.gov/aboutstate/.

38 Wright, Thomas, “Trump's 19th Century Foreign Policy”, Politico Magazine, 20 de junio de 2016. Disponible en: https: / /www.politico.com/magazine/story/2016/01/donald-trumpforeign-policy-213546. 
gobernanza global — que el propio EE UU ayudó a diseñar y a mantener-, tomando como ejemplo a la Organización de las Naciones Unidas para la Educación, la Ciencia y la Cultura (UNESCO) y al Consejo de Derechos Humanos de la ONU.

A. El Acuerdo de París: el debilitamiento del régimen de gobernanza del cambio climático

El cambio climático es quizá la amenaza más grande que enfrenta el planeta, y el Acuerdo de París constituye el instrumento multilateral más reciente, operativo y prometedor para combatir el cambio climático. ${ }^{39}$ Por ello, el anuncio del retiro de EE UU de éste, el 1o. de junio de 2017, fue condenado por organismos internacionales y gobiernos de diferentes países. ${ }^{40}$

Este anuncio también ejemplificó la promesa de campaña de Trump sobre retirarse o renegociar convenciones internacionales que a su parecer no eran beneficiosas para su país. Sin embargo, para el resto del mundo esto implicó dar la espalda al régimen de gobernanza del cambio climático y a la vez dejar un vacío en el liderazgo del tema, sin mencionar el impacto financiero y en la cooperación.

Con el Acuerdo de París, por primera vez se habían logrado compromisos específicos para el largo plazo, y EE UU demostró el mayor interés en cumplir con sus disposiciones, sin olvidar al activismo que tuvo en las negociaciones. Sin embargo, la decisión de Trump debilitó ese régimen.

La tragedia de la decisión del gobierno de Trump la semana pasada fue que el Acuerdo de París marcó un parteaguas en las negociaciones interminables e imposibles entre los 190 Estados miembros de las Naciones Unidas acerca de los objetivos de las temperaturas a largo plazo... y las negociaciones entre los mayores emisores. Los compromisos hechos en París se centraron en medidas y acciones

39 Tudela, Fernando, "Trump y el Acuerdo de París”, Nexos, 1 de octubre de 2017. Disponible en: https: / / www.nexos.com. mx/?p=33948.

40 Conolly, Kate y Watts, Jonathan, "World Leaders React After Trump Rejects Paris Climate Deal”, The Guardian, 2 de junio de 2017. Disponible en: https: / /www.theguardian.com/ environment/2017/jun/01/trump-withdraw-paris-climate-deal-world-leaders-react. 
Esta revista forma parte del acervo de la Biblioteca Jurídica Virtual del Instituto de Investigaciones Jurídicas de la UNAM

DOI: http://dx.doi.org/10.22201/iij.24487872e_2020.20.14491

específicas que los países con las mayores emisiones están dispuestos a tomar para reducir las emisiones hoy y no en el futuro lejano (la traducción es propia). ${ }^{41}$

Lo anterior marcó un gran progreso en el combate al cambio climático, pues tanto Estados Unidos de América como China - los mayores emisores - estaban de acuerdo con los compromisos establecidos en el instrumento. Tan solo EE UU es el segundo emisor a nivel mundial de gases de efecto invernadero (GEI) — con más de 6.3 millones de emisiones - ${ }^{42}$ Por tanto, su voluntad de formar parte del Acuerdo constituyó el reconocimiento de su responsabilidad como uno de los principales países emisores de GEI junto con China, situación que fortaleció la asunción de un compromiso compartido en todo el mundo, eliminó los obstáculos más notorios para avanzar en las negociaciones del Acuerdo y logró consenso entre la comunidad internacional. ${ }^{43}$ El retiro del instrumento no es tan simple. El artículo 28 del Acuerdo de París que contempla el proceso de denuncia del mismo, establece que cualquiera de las partes podrá denunciarlo mediante notificación por escrito al depositario en cualquier momento después de que hayan transcurrido tres años a partir de la fecha de entrada en vigor para esa parte. Asimismo, la denuncia surtirá efecto al cabo de un año contado desde la fecha en que el depositario haya recibido la notificación correspondiente o, posteriormente, en la fecha que se indique en la notificación. Derivado de lo anterior, la denuncia de EE UU no podrá hacerse efectiva hasta el 4 de noviembre de 2020, y aunque el presidente Trump en un inició planteó la renegociación del Acuerdo, esto sería prácticamente inviable. ${ }^{44}$

Es de resaltar que el anuncio de Donald Trump generó gran oposición dentro de los círculos políticos estadounidenses, ya que se desarrollaron diversas iniciativas como la impulsada por catorce estados que forma-

41 Nordhaus, Ted y Trembath, Alex, “Trump's Paris Agreement Withdrawal in Context”, Foreign Affairs, 5 de junio de 2017. Disponible en: https://www.foreignaffairs.com/articles/ world/2017-06-05/trumps-paris-agreement-withdrawal-context.

42 Datos del Banco Mundial, más información disponible en: https: //datos.bancomundial. org/indicador/EN.ATM.GHGT.KT.CE?view = chart.

43 La Casa Blanca, Oficina de la Secretaría de Prensa, “U.S.-China Joint Announcement on Climate Change”, 11 de noviembre de 2014. Diponible en: https: / /obamawhitehouse.archives.gov/ the-press-office/2014/11/11/us-china-joint-announcement-climate-change.

44 Tudela, Fernando, op. cit. 
ron la Alianza de los Estados Unidos para el Clima y 377 alcaldes formaron el grupo US Climate Mayors, ambos grupos con los objetivos de adoptar, cumplir y sostener los compromisos del Acuerdo de París. ${ }^{45}$

Una vez que EE UU deje de ser parte de ese instrumento, sin duda se dificultaría la estrategia internacional para enfrentar el cambio climático. Aunque el Acuerdo se debilitó sigue siendo efectivo y estando presente, pues más de 190 países que representan el 80\% de las emisiones globales son signatarios, y de los cuales, más de180 lo han ratificado. ${ }^{46}$

B. El Acuerdo Nuclear de Irán: de la estabilidad a la incertidumbre en el Medio Oriente

El JCPOA se refiere a una serie de medidas voluntarias para limitar el programa nuclear de Irán, con el objetivo de que éste no evolucione hasta convertirse en una fuente de inestabilidad Medio Oriente a cambio de levantar las sanciones de las que el país era sujeto. El JCPOA fue negociado por los cinco miembros permanentes del CSONU (P5), Alemania (P5 + 1), e Irán. Su cumplimiento tiene implicaciones a nivel mundial, ya que se trata de un tema que afecta a la humanidad en su totalidad.

Inicialmente, alcanzar el acuerdo parecía imposible debido a que se trataba de países cuyas relaciones estaban marcadas por el conflicto y la falta de confianza. Sin embargo, los negociadores lograron alinear sus objetivos para contribuir con la estabilidad en Medio Oriente. El instrumento fue un triunfo para el multilateralismo debido a que conjuntaba visiones diferentes y contenía medidas para verificar su cumplimiento. ${ }^{47}$

El JCPOA no fue firmado por ninguna de las partes y no incluye provisiones relativas a la ratificación, a la denuncia y la entrada en vigor. Al no estar suscrito se considera una serie de medidas voluntarias, no obstante, se puede argumentar que tiene un estatus jurídico especial ya que está avalado por la Resolución 2231 (2015) del CSONU, que a su vez contiene

45 Idem.

46 Más información sobre el Acuerdo de París disponible en: https: / / treaties.un.org/Pages / ViewDetails.aspx?src=IND\&mtdsg_no $=X X V I I-7-d \&$ chapter $=27 \&$ clang $=\_$en .

47 Sherman, Wendy, "How We Got the Iran Deal”, Foreign Affairs, vol. 97, núm. 5, septiembre-octubre de 2018. Disponible en: https: / / www.foreignaffairs.com / articles / 2018-08-13 / howwe-got-iran-deal. 
medidas voluntarias y obligatorias. ${ }^{48}$ Lo anterior, de alguna manera lo hace vinculante y otorga obligaciones jurídicas bajo la Carta de las Naciones Unidas, es decir, crea obligaciones internacionales.

Durante su campaña, Donald Trump expresó que el Acuerdo no era justo para su país debido a que las ambiciones nucleares de Irán planteaban un grave riesgo a la seguridad internacional. Por ello, el 8 de mayo de 2018, el presidente Trump anunció la reimposición de sanciones a Irán, esto es, su salida del JCPOA. ${ }^{49}$ Ante esa situación, la aplicación de posibles represalias ha hecho sonar las alarmas en cuestiones de seguridad, si bien el Acuerdo no era perfecto, ofrecía la seguridad de que Irán no obtendría un arma nuclear y los mecanismos de verificación dieron señales que el país había cumplido su parte del trato.

El Acuerdo no contiene ninguna disposición para denunciarlo, sin embargo, al salir una parte — en este caso EE UU — se deja la posibilidad para las otras partes de permanecer, incluyendo a Irán. ${ }^{50}$ Una vez más, el desdén del presidente Trump a los logros del multilateralismo, afecta la estabilidad de una región completa.

\section{El retiro de la UNESCO: del poder suave al olvido del liderazgo}

La UNESCO es una de las organizaciones más conocidas del Sistema de las Naciones Unidas, pues además de haber sido una de las primeras en establecerse tras la creación de la ONU, es conocida por su lista de sitios patrimonio de la humanidad que ayuda a preservar, difundir y mantener el patrimonio, además de promover la cooperación en torno al intercambio de ideas, cultura e información.

El 12 de octubre de 2017, Donald Trump —a través del Departamento de Estado - anunció el retiro de su país de la UNESCO con efectos

48 Mulligan, Stephen P., "Withdrawal from International Agreements: Legal Framework, the Paris Agreement, and the Iran Nuclear Agreement", Congressional Research Service, 4 de mayo de 2018, p. 20. Disponible en: https:/ / fas.org/sgp/crs/row/R44761.pdf.

49 La Casa Blanca, "President Donald J. Trump is Ending United States Participation in an Unacceptable Iran Deal”, Fact Sheets, 8 de mayo de 2018. Disponible en: https://www. whitehouse.gov/briefings-statements / president-donald-j-trump-ending-united-states-participationunacceptable-iran-deal/.

50 Kerr, Paul K. y Katzman, Kenneth, "Iran Nuclear Agreement and U.S. Exit”, Congressional Research Service, 20 de julio de 2018, p. 22. Disponible en: https://fas.org/sgp/crs/nuke/ R43333.pdf. 
a partir de diciembre de 2018, bajo los argumentos que la Organización precisa de reformas profundas, que es un organismo altamente politizado, y que tiene un marcado sesgo en contra de Israel. ${ }^{51}$

La UNESCO fue el primer organismo internacional donde Palestina fue admitido como miembro. De hecho, bajo la administración Obama, EE UU había dejado de hacer su aportación financiera a la Organización —alrededor del $22 \%$ de su presupuesto total — en apoyo a Israel tras la admisión de Palestina. ${ }^{52}$ Ahora, la decisión de Trump es más drástica, pues va más allá de la reducción en el financiamiento, es parte del patrón de abandono de las instituciones multilaterales.

Irina Bokova, entonces directora general de la UNESCO, lamentó la decisión y la consideró como una pérdida para el multilateralismo. Afirmó que la labor conjunta era esencial para crear respuestas para la paz y la seguridad, combatir el terrorismo y antisemitismo, así como luchar contra la ignorancia y la discriminación a largo plazo. ${ }^{53}$

Con esta decisión, y la posibilidad de cambiar su estatus al de Estado observador, ese país perdería liderazgo y la oportunidad de usar su voto en los asuntos propios de la Organización - como una posible reforma o impulsar mejoras que el propio EE UU ha señalado-.

D. El Consejo de Derechos Humanos: un enfoque desde la politización

El Consejo de Derechos Humanos es un organismo del sistema de las Naciones Unidas compuesto por 47 Estados miembro, que tiene el objetivo de examinar la situación de los derechos humanos en el mundo y de formular recomendaciones. Es de resaltar que sustituyó a la Comisión de Derechos Humanos en 2006, organismo percibido como débil y desgastado,

51 Rosenberg, Eli y Morello, Carol, “U.S. Withdraws from UNESCO, the U.N.'s Cultural Organization, Citing Anti-Israel Bias”, TheWashington Post, 12 de octubre de 2017. Disponible en: https: / / www.washingtonpost.com/news/post-nation/wp/2017/10/12/u-s-withdraws-fromunesco-the-u-n-s-cultural-organization-citing-anti-israel-bias $/$ ?utm_term $=.2 b 4098 b 539 b 9$.

52 Fisher, Max, “Trump Prepares Orders Aiming at Global Funding and Treaties”, The New York Times, 25 de enero de 2017. Disponible en: https://www.nytimes.com/2017/01/25/us/ politics/united-nations-trump-administration.html.

53 "Statement by Irina Bokova, Director General of UNESCO, on the occasion of the Withdrawal by the United States of America from UNESCO”, UNESCO, 12 de octubre de 2017. Disponible en: https://en.unesco.org/news/statement-irina-bokova-director-general-unescooccasion-withdrawal-united-states-america-unesco. 
y que sirvió como foro de confrontaciones políticas. Adicionalmente, su efectividad fue altamente cuestionada ya que su membresía — de 53 Estados_ l llevó a más negociaciones, a resoluciones más duras y a menos acciones decisivas, transformándola en una "Asamblea General en miniatura". ${ }^{54}$

Es claro que el Consejo enfrenta retos debido a que entre sus miembros se encuentran Estados que han tenido serias acusaciones sobre violaciones a los derechos humanos, como Venezuela y la República Democrática del Congo. ${ }^{55}$ Sin embargo, a diez años de su creación, ha tenido logros en la arena multilateral como el nombramiento de misiones de investigación para Siria, Eritrea o Burundi; la respuesta a situaciones urgentes mediante periodos extraordinarios de sesiones, la creación de comisiones de investigación, el nombramiento de relatores especializados en determinados temas, el Examen Periódico Universal,y un método de denuncias innovador.

Anteriormente, el presidente George W. Bush no quiso participar en el proceso para obtener un asiento en 2006. No obstante, el presidente Obama logró uno en 2009 como parte de su estrategia de política exterior y para demostrar la importancia que le confería a la protección de los derechos humanos a nivel mundial, además de considerar que la presencia de aquel país en el Consejo daría una mayor voz a las víctimas de violaciones de derechos humanos que en ese momento eran atribuibles a distintos regímenes autoritarios de Medio Oriente. ${ }^{56}$

Como parte de la estrategia de alejamiento de las instituciones multilaterales, en marzo de 2017, el secretario de Estado, Rex Tillerson, amenazó con retirar a EE UU del Consejo de Derechos Humanos bajo el

54 UN Watch, “This Year's UN Commission on Human Rights Structural Problems and Political Gamesmanship”, issue 25, 14 de abril de 1999. Disponible en: https: / www.unwatch. org/issue-25-years-un-commission-human-rights-structural-problems-political-gamesmanship/.

55 Los miembros del Consejo son electos para un periodo de tres años. Venezuela termina su membresía en 2019 — tiene posibilidad de reelección — y la República Democrática del Congo en 2020. Más información disponible en la página web del Consejo de Derechos Humanos de la Organización de las Naciones Unidas: https: //www.ohchr.org/EN/HRBodies/ HRC/Pages /HRCElections. aspx.

56 Un ejemplo de ello fue la condena de Libia y la propuesta de su expulsión del Consejo de Derechos Humanos en febrero de 2011, como parte de las acciones del gobierno estadounidense se convocó a una sesión especial en el Consejo sobre la crisis de ese país y se propuso la creación de una comisión internacional de investigación. "Obamas Speech on Lybia (Text)”, The New York Times, 23 de febrero de 2011. Disponible en: https: / /www.nytimes. com/2011/02/24/us/politics/24obama-statement-libya.html. 
argumento de que éste no cumple con su cometido en la mejora de los derechos humanos, y la existencia de un fuerte prejuicio en contra de Israel. ${ }^{57}$

La amenaza del retiro se materializó el 19 de junio de 2018, tras el anuncio de Nikki Hailey, Representante Permanente de EE UU ante la ONU. ${ }^{58}$ Este retiro es especialmente devastador debido a que ese país había sido el defensor por excelencia de la causa de los derechos humanos en el mundo. A pesar de los retos que enfrenta el Consejo, no se pueden minimizar los logros evidentes que ha tenido en la arena multilateral, como los mencionados.

\section{CONSIDERACIONES FINALES}

1. Decisiones recientes en la política exterior de Estados Unidos de América: ¿temas pendientes en el multilateralismo?

La política exterior abanderada por el presidente Donald Trump sin duda tendrá efectos bilaterales, regionales y multilaterales. Además de los ejemplos mencionados, destacan los efectos en el comercio internacional derivados del retiro del TPP pocos días después de rendir protesta, ${ }^{59}$ la amenaza de abandonar la $\mathrm{OMC}^{60}$ y la consecuente adopción de una postura altamente proteccionista que ha desencadenado guerras comerciales con antiguos socios como China. Asimismo, se ha pronunciado por recortar el financiamiento a las instituciones como la ONU, lo que tendrá efectos directos y tangibles en mecanismos útiles como las Operaciones de Mantenimiento

57 Revesz, Rachel, "Rex Tillerson Threatens to Withdraw from UN Human Rights Council to Improve Human Rights", The Independent, 15 de marzo de 2017. Disponible en: https: / / www.independent.co.uk/news / world / americas / rex-tillerson-un-human-rights-council-us-secretarystate-china-saudi-arabia-egypt-a7630531.html.

58 Harris, Gardiner, "Haley Blames Watchdog Groups for U.S. Withdrawal from U.N. Rights Council”, The New York Times, 20 de junio de 2018. Disponible en: https: / /www.nytimes. com/2018/06/20/us/politics/haley-un-human-rights-council.html.

59 Oficina del Representante de Comercio de Estados Unidos de América, "The United States Officially Withdraws from the Trans-Pacific Partnership”, 30 de enero de 2017. Disponible en: https://ustr.gov/about-us/policy-offices/press-office/press-releases/2017/january/ US-Withdraws-From-TPP.

60 Micklethwait, John et al. , "President Trump Threatens to Withdraw U.S. from the World Trade Organization «If They Don't Shape Up»”, TIME, 30 de agosto de 2018. Disponible en: http: / / time.com/5383420/trump-world-trade-organization/. 
de la Paz (OMP $)^{61}$ cuyos mandatos fueron, en parte, diseñados por EE UU. De hecho, el artículo 17 de la Carta de la ONU establece disposiciones particulares sobre los aspectos financieros y presupuestarios de los Estados miembros con respecto de la propia Organización, sus órganos y organismos. También, con base en las resoluciones adoptadas por la AGONU, y que podrían llegar a ser consideradas como soft law, los Estados han establecido tasas de prorrateo para la financiación de las OMP.

Consistente con la política de alejarse de las instituciones multilaterales, el gobierno estadounidense ha asumido una postura defensiva frente a los tribunales internacionales, como la Corte Penal Internacional (CPI). ${ }^{62}$ El 10 de septiembre de 2018, John Bolton, asesor de seguridad nacional de EE UU, expresó que ese país adoptaría cualquier medida que considerara necesaria para proteger a su pueblo y a sus aliados contra las acusaciones que ese tribunal había instaurado en contra de nacionales por la comisión de diversos crímenes - tipificados por el Estatuto de la CPI - durante el conflicto en Afganistán. Bolton señaló que EE UU no cooperaría con el tribunal, y expresó que, para todos los efectos, la CPI ya está muerta para ellos. ${ }^{63}$ Además, precisó que esa investigación no había sido incoada por Afganistán ni por algún otro Estado, y que de ser necesario EE UU valoraría recurrir al CSONU para restringir la actuación de la Corte y asegurarse que no ejerciera jurisdicción sobre estadounidenses y nacionales de otros Estados que no hubieran ratificado el Estatuto de Roma. Como reacción a esa declaración, la Corte emitió un comunicado de prensa en el que aseguró que, como tribunal de justicia, continuará realizando su labor sin desalentarse, de conformidad con los principios y la idea general del Estado de derecho. ${ }^{64}$

A pesar de ello, no es la primera ocasión en que EE UU cuestiona la jurisdicción del tribunal. En 2005, el presidente George W. Bush instruyó

61 Los comentarios al respecto de este tema están disponibles en: https://usun.usmission. gov/remarks-at-a-un-security-council-open-debate-on-peacekeeping/.

62 Embajada y Consulado de Estados Unidos de América en Países Bajos, "Fact Sheet: Protecting American Constitutionalism and Sovereignity from the International Criminal Court", 10 de septiembre de 2010. Disponible en: https://nl.usembassy.gov/fact-sheet-protecting-american-constitutionalism-and-sovereignty-from-the-international-criminal-court/.

63 “John Bolton Threatens ICC with US Sanctions", BBC News, 11 de septiembre de 2018. Disponible en: https: //www.bbc.com/news/world-us-canada-45474864.

64 Corte Penal Internacional, "The ICC will continue its independent and impartial work, undeterred", 12 de septiembre de 2018. Disponible en: https://www.icc-cpi.int/Pages/item. aspx?name $=$ pr1406. 
el retiro de la firma del Estatuto de la CPI, ${ }^{65}$ procedimiento que fue cuestionado en el derecho internacional a pesar de no existir disposición expresa en contrario en el instrumento jurídico y en la Convención de Viena sobre el Derecho de los Tratados.

EE UU ha puesto en entredicho a las instituciones del derecho internacional, lo que puede acarrear otros cuestionamientos y una posible apatía o enojo por parte de los actores que han respetado las normas, independientemente de que éstas los beneficien directamente. Sin embargo, corresponderá a la comunidad internacional dar seguimiento y vigilar ese tipo de decisiones a la luz de las normas jurídicas que establecen procedimientos específicos para el retiro, la denuncia, o las medidas por adoptar ante el quebrantamiento de obligaciones internacionales por parte de un sujeto de derecho. Del mismo modo, en la manera que continúen adoptándose decisiones en materia de política exterior que cuestionen el andamiaje internacional, tendremos que mantenernos atentos al rumbo que tome el multilateralismo y al grado de resiliencia de las normas jurídicas y las instituciones.

2. Algunas implicaciones de la política exterior de Estados Unidos de América frente al derecho internacional

En todos los casos expuestos en este artículo, EE UU fue parte de las negociaciones y del diseño de las instituciones mencionadas, incluso de su defensa, su activismo alentó su desarrollo. El retiro y desdén por el orden que construyó y defendió después de la Segunda Guerra Mundial traerá para este país la pérdida de su prestigio, algo que será difícil de recuperar ${ }^{66}$ por las administraciones subsecuentes en el largo plazo.

Con la llegada al poder de Donald Trump, la política exterior de EE UU parece ser guiada por una visión maniquea y simplista del mundo, que rompe con lo construido en los años previos y que ha llevado a hablar de la política exterior en la era de Twitter y Trump.

65 Departamento de Defensa de Estados Unidos de América, "U.S. Withdraws from International Criminal Court Treaty”, 7 de mayo de 2002. Disponible en: https: / / archive.defense. gov/news/newsarticle. aspx?id=44089.

66 Byman, Daniel L., "Recovering from the Trump Foreign Policy", The Brookings Institution, 18 de junio de 2018. Disponible en: https://www.brookings.edu/blog/order-fromchaos/2018/06/18/recovering-from-the-trump-foreign-policy/. 
Ahora bien, esto lleva a pensar que, bajo la actual administración, EE UU difícilmente cumplirá sus compromisos internacionales. Sin embargo, esta idea no debe suponer que el multilateralismo fracasará o desaparecerá, pues a pesar de todo, aún es la mejor manera de enfrentar los problemas que le son comunes a la humanidad. De hecho, durante los últimos setenta años las instituciones multilaterales han jugado un papel fundamental en los esfuerzos globales orientados a robustecer la gobernanza mundial y mantener la paz y la seguridad internacionales; y después de la crisis financiera, esas instituciones son más necesarias que nunca. ${ }^{67}$

El multilateralismo ha beneficiado continuamente al mundo y ha ayudado a crear un sistema de gobernanza que, de manera progresiva, ha atendido retos que le son comunes a toda la comunidad internacional (por ejemplo, cambio climático, transparencia, inversión, telecomunicaciones, desarrollo sostenible, entre otros), aunque claro, el sistema multilateral siempre es y será perfectible.

Hay quienes afirman que, para fortalecer y preservar este orden, se requiere de un renovado liderazgo de Estados Unidos de América, ${ }^{68}$ ya que él mismo lo ha defendido tradicionalmente a través de su poder militar, de su economía, o de su sistema de alianzas. Pese a ello, se debe percibir un objetivo concreto en su política exterior, y en el centro de la misma está el entendido de que sus intereses fundamentales se verán mejor defendidos si mantiene su apoyo a este sistema. ${ }^{69}$

En realidad, las situaciones descritas no ponen en entredicho la arquitectura multilateral construida durante la segunda mitad del siglo XX, debido a que el sistema está lo suficientemente arraigado como para que otros Estados, incluso con un mayor sentido de compromiso, tomen el lugar que históricamente conquistó EE UU. Esto no significa que las denuncias y desdenes de ese país hacia el sistema, del cual fue arquitecto, no tengan implicaciones para otros Estados; sin embargo, no podemos dejar

67 Thomson, Stéphanie, "4 Trends that Will Define the Future of US Foreign Policy”, World Economic Forum, 26 de abril de 2016. Disponible en: https://www.weforum.org/ agenda /2016/04/4-trends-that-will-define-the-future-of-us-foreign-policy/.

68 Kagan, Robert et al., Strengthening the Liberal World Order. A World Economic Forum White Paper, World Economic Forum, abril de 2016, p. 2. Disponible en: http: / /www3. weforum.org/ docs/WEF_US_GAC_Strengthening_Liberal_World_Order_White_Paper_US.pdf.

69 Ibidem, p. 5. 
de lado que esta situación puede representar una oportunidad para llenar esos vacíos de poder, por ejemplo, bajo la dirección de potencias medianas.

A estas alturas de su mandato (2020), se puede afirmar que el estilo de liderazgo de Donald Trump ha afectado la relación del país con el mundo, además de dudar de la seriedad de las decisiones que adopta, sobre todo si se pone en consideración el rechazo mostrado a las opiniones de sus asesores y a las provenientes de expertos en los temas. Asimismo, el mandatario se ha mantenido fiel a sus ideas de campaña sobre las que ha construido una política exterior consistente con el discurso nacionalista y proteccionista que lo caracteriza en el ámbito político: el retiro del TPP, el desprecio hacia el TLCAN, el cuestionamiento sobre su compromiso con la OTAN, la admiración y adulación pública a los líderes de Rusia, Turquía, Arabia Saudita y China, el lanzamiento de amenazas a través de Twitter, y el acompañamiento de personal sin experiencia en la política exterior. ${ }^{70}$ La salida de EE UU de estos regímenes e instituciones, y la negligencia de su propio liderazgo, ciertamente debilitan al multilateralismo, pero no lo rompen porque es un sistema profundamente arraigado del cual dependen muchos países y fenómenos, además de la influencia de sus valores para atender los problemas que son comunes.

Existen grandes temas que definirán la agenda global $-\mathrm{y}$ en donde a falta del liderazgo de EE UU es posible que surjan nuevos líderes- en los próximos años, a saber: la reforma de las instituciones globales financieras - pues el mundo no es el mismo que cuando surgieron el Banco Mundial o el Fondo Monetario Internacional_-; los retos a la seguridad frente al terrorismo y las tensiones regionales en Asia o Medio Oriente, los efectos del cambio climático, así como la atención que demanda el impacto de la movilidad humana, en particular, la mitigación de los riesgos que enfrentan las personas migrantes y refugiadas y los beneficios de los movimientos humanos en todo el mundo. ${ }^{71}$ Una de las opciones es usar la crisis como motivo

70 Saunders, Elizabeth, op. cit.

71 El 19 de diciembre de 2018, la Asamblea General de la ONU adoptó el Pacto Mundial para la Migración Segura, Ordenada y Regular, mediante la resolución A/RES/73/195, por 152 votos a favor (incluyendo a México), 5 en contra (entre ellos EE UU) y 12 abstenciones. Para información más detallada de la votación, consúltese la Biblioteca Digital de la Organización de las Naciones Unidas, disponible en: https://digitallibrary.un.org/ record $/ 1656414 ? \ln =e n$. 
para la reforma. ${ }^{72}$ Es la oportunidad para poner a prueba la resiliencia del derecho y de las instituciones internacionales, en el que tradicionalmente EE UU tenía gran influencia y hegemonía, como el caso del CSONU, en el que ha dado forma a las resoluciones, mandatos y mecanismos que emanan del órgano.

Día a día todas las instituciones contribuyen con la estabilidad global y fueron diseñadas para resistir el paso del tiempo: incluyen décadas de encuentros diplomáticos para llegar a soluciones negociadas, contienen mecanismos flexibles para el ajuste de sus miembros sin que tengan que retirarse. ${ }^{73}$ Es cierto que preocupa la tendencia hacia el aislacionismo y proteccionismo, pero más allá del retiro del orden internacional existe un alto grado de cumplimiento de sus normas jurídicas en el comercio, en las inversiones, en el transporte, en las comunicaciones, en la movilidad, etcétera. Por ese motivo, María Fernanda Espinosa Garcés, presidenta de la AGONU, expresó, durante la apertura del Segmento de Alto Nivel del Debate General del septuagésimo tercer periodo ordinario de sesiones de la Asamblea, que el multilateralismo constituye la única respuesta posible a los problemas globales que enfrentamos. Debilitarlo o ponerlo en cuestión solo genera inestabilidad y desconcierto, desconfianza y polarización. ${ }^{74}$

El retiro y rechazo que EE UU muestra al sistema y al orden jurídico internacionales, pone en relieve el miedo permanente y el debate enraizado sobre el carácter normativo del derecho internacional, y sobre la ineficacia de la comunidad internacional para sancionar las violaciones a los preceptos que ella misma construye. Sin embargo, ni su retiro de esos organismos internacionales o de las convenciones que ha adoptado podrían desarticular el multilateralismo, el solo incumplimiento de las normas internacionales no suprime su valor jurídico ni minimiza la responsabilidad en la que se incurre por contravenirlas. Lo que da el valor normativo al derecho interna-

72 Pisani-Ferry, Jean, “Can Multilateralism Adapt?", Bruegel, 3 de julio 2018. Disponible en: http://bruegel.org/2018/07/can-multilateralism-adapt/.

73 Vabulas, Felicity, "Trump is Pulling the U.S. out of UNESCO. The Bigger Pattern is the Problem”, TheWashington Post, 16 de octubre de 2017. Disponible en: https: / /www.washingtonpost.com/news / monkey-cage/wp/2017/10/16/trump-is-pulling-the-u-s-out-of-unesco-the-biggerpattern-is-the-problem $/$ ?noredirect $=$ on\&utm_term $=.84 \mathrm{ce} 10 \mathrm{bf} 52 \mathrm{a} 5$.

74 "La ONU es tan relevante como cuando se fundó la Organización, dice la presidenta de la Asamblea General”, Noticias ONU, 25 de septiembre de 2018. Disponible en: https://news. un.org/es/story/2018/09/1442292. 
cional, y en específico al sistema multilateral, es que esas normas jurídicas y sus instituciones logran aproximar a la comunidad internacional al fin último de un sistema y orden jurídicos, es decir, la seguridad y la certeza de que las normas que construyen los sujetos son válidas y aplicables, y no solo funcionan como producto del consentimiento y buena fe. De hecho, el retiro de diversas instituciones internacionales revela la importancia de los principios pacta sunt servanda (los pactos deben ser cumplidos) y dura lex, sed lex (la ley es dura pero es la ley): si EE UU no está dispuesto a cumplir, entonces no existe una dictadura internacional que lo obligue a permanecer en los foros o en los acuerdos, sin embargo, a través de su membresía y papel en la comunidad internacional ha construido los mecanismos correspondientes para hacer cumplir las normas jurídicas. Esto demuestra que el orden jurídico internacional puede ser cuestionado en su eficacia, pero no así en su valor jurídico. Sobre esa percepción, Thomas Frank se pronunció en 2006:

En el corto plazo, deberíamos imaginar un mundo en el que Estados Unidos de América viole la prohibición (en contra del uso de la fuerza armada) y gaste menos esfuerzo para disuadir o responder a las violaciones de otros. Algunos podrían decir que esto reducirá la hipocresía de EE UU, y también significará menos apoyo para muchas normas jurídicas internacionales básicas (la traducción es propia). ${ }^{75}$

Más allá de eso, las normas jurídicas internacionales seguirán regulando el actuar de EE UU y de los demás sujetos, como producto de la costumbre, de la codificación y de la práctica, pero por encima de cualquier circunstancia como producto de la expresión de su propia voluntad por encontrar soluciones comunes que atañen al mundo entero.

\section{BiBLIOGRAFíA}

BoOn, Kristen, "President Trump and the Future of Multilateralism", Emory International Law Review, Atlanta, vol. 31, 2017. Disponible en: http:// law.emory.edu / eilr / recent-developments / volume-31 / essays / president-trumpfuture-multilateralism.html.

Borger, Julian, "In Pledging to Put «America first», Trump Holds the World at his Mercy”, The Guardian, 20 de enero de 2017. Disponible en:

75 Hakimi, Monica, "International Law in the Age of Trump", EJIL:Talk!, 28 de febrero de 2017. Disponible en: https://www.ejiltalk.org/international-law-in-the-age-of-trump/. 
Esta revista forma parte del acervo de la Biblioteca Jurídica Virtual del Instituto de Investigaciones Jurídicas de la UNAM

https: / / www.theguardian.com / world/2017/jan/20/trump-inaugurationamerica-first-foreign-policy.

Byman, Daniel L., "Recovering from the Trump Foreign Policy", The Brookings Institution, 18 de junio de 2018. Disponible en: https: / / www.brookings. edu /blog/order-from-chaos /2018/06/18/recovering-from-the-trump-foreignpolicy/.

CARrillo SuÁreZ, Agustín Eduardo, "Los organismos internacionales", Curso de actualización de profesores de derecho internacional privado, Cuadernos de trabajo del Seminario de Derecho Internacional, México, UNAM, Facultad de Derecho, 2009. Disponible en: ttps: / / archivos.juridicas.unam. $\mathrm{mx}_{\mathrm{N}}$ www/bjv/libros/9/4056/12.pd.

CONOLlY, Kate y WaTTS, Jonathan, "World Leaders React AfterTrump Rejects Paris Climate Deal", The Guardian, 2 de junio de 2017. Disponible en: https: / / www.theguardian.com/environment/2017/jun/01/trump-withdraw-paris-climate-deal-world-leaders-react.

Corell, Hans, "The Mandate of the United Nations Security Council in a Changing World", en Ebbesson, Jonas et al. (eds.), International Law and Changing Perceptions of Security: Liber Amicorum Said Mahmoudi, Leiden-Boston, Brill-Martinus Nijhoff Publishers, 2014. Disponible en: http: / /www. havc.se/res/SelectedMaterial / 20142224ilperceptionsofsecurity.pdf.

FAus, Joan, "La doctrina exterior de Obama, en 11 claves", El País, 15 de marzo de 2016. Disponible en: https://elpais.com/internacional/2016/03/14/estados_unidos/1457971957_819516.html.

FISHER, Max, "Trump Prepares Orders Aiming at Global Funding and Treaties”, The New York Times, 25 de enero de 2017. Disponible en: https: / / www.nytimes.com/2017/01/25/us/politics/united-nations-trump-administration.html.

FOrero RodríGUEZ, Mario A., "Integración y multilateralismo en el marco de las relaciones económicas internacionales”, Revista Análisis Internacional, núm. 3, 2011. Disponible en: https://revistas.utadeo.edu.co/index. php/RAI/article/download/72/75.

GOLDSMiTH, Jack, "The Contributions of the Obama Administration to the Practice and Theory of International Law", Harvard International Law Journal, Massachusetts, vol. 57, núm. 2, 2016. Disponible en: https: / / harvardilj.org/wp-content/uploads/sites /15/Goldsmith_HILJ-Online-Version_23June-2016_Final.pdf. 
Esta revista forma parte del acervo de la Biblioteca Jurídica Virtual del Instituto de Investigaciones Jurídicas de la UNAM

Groves, Steven y Schaefer, Brett, “The U.N. Human Rights Council: No Better for Obama's Engagement”, The Heritage Foundation, 2009. Disponible en: https: //www.heritage.org/report/the-un-human-rights-council-nobetter-obamas-engagement.

HaKIMI, Mónica, "International Law in the Age of Trump”, EJIL: Talk!, 28 de febrero de 2017. Disponible en: https: / / www.ejiltalk.org/internationallaw-in-the-age-of-trump/.

HARRIS, Gardiner, "Haley Blames Watchdog Groups for U.S. Withdrawal from U.N. Rights Council”, The NewYork Times, 20 de junio de 2018. Disponible en: https://www.nytimes.com/2018/06/20/us/politics/haley-unhuman-rights-council.html.

"John Bolton Threatens ICC with US Sanctions", BBC News, 11 de septiembre de 2018. Disponible en: https://www.bbc.com/news/world-us-canada-45474864.

KaGAn, Robert et al., Strengthening the Liberal World Order. A World Economic Forum White Paper, World Economic Forum, abril de 2016. Disponible en: http: //www3.weforum.org/docs/WEF_US_GAC_Strengthening_Liberal_ World_Order_White_Paper_US.pdf.

KeOhane, Robert O. y Martin, Lisa L., “The Promise of Institutionalist Theory”, International Security, Massachusetts, vol. 20, núm. 1, 1995. Disponible en: https://www.uio.no/studier/emner/hf/iakh/HIS4421/ h11/undervisningsmateriale/HIS4421_KeohaneMartinInstitutionalism.pdf.

KerR, Paul K. y Katzman, Kenneth, "Iran Nuclear Agreement and U.S. Exit”, Congressional Research Service, 20 de julio de 2018. Disponible en: https: / / fas.org/sgp/crs/nuke/R43333.pdf.

Lagos, Enrique, "Algunas tendencias del derecho internacional a principios del siglo XXI”, Anuario Mexicano de Derecho Internacional, México, vol. V, 2005. Disponible en: https: / / revistas.juridicas. unam.mx/index.php/ derecho-internacional/article/view/122/184\#N11.

MicKlethWAiT, John et al., "President Trump Threatens to Withdraw U.S. from the World Trade Organization «If They Don't Shape Up»", TIME, 30 de agosto de 2018. Disponible en: http: / / time.com/5383420/trumpworld-trade-organization/.

Mulligan, Stephen P., "Withdrawal from International Agreements: Legal Framework, the Paris Agreement, and the Iran Nuclear Agreement", Congressional Research Service, 4 de mayo de 2018. Disponible en: https: / / fas.org/sgp/crs/row/R44761.pdf. 
Esta revista forma parte del acervo de la Biblioteca Jurídica Virtual del Instituto de Investigaciones Jurídicas de la UNAM

Mulligan, Stephen P., "Withdrawal from the Iran Nuclear Deal: Legal Authorities and Implications", Congressional Research Service, 17 de mayo de 2018.

MuRdock, Sebastian, "Majority of Republicans Said «No» When Obama Wanted to Launch a Strike on Syria”, Huffpost, 4 de julio de 2017. Disponible en: https://www.huffpost.com/entry/republicans-strike-syriatrump_n_58e6f71de4b051b9a9da355d.

Nordhaus, Ted y Trembath, Alex, “Trump's Paris Agreement Withdrawal in Context”, Foreign Affairs, 5 de junio de 2017. Disponible en: https: / / www. foreignaffairs.com / articles / world / 2017-06-05 / trumps-paris-agreementwithdrawal-context.

"Obamas Speech on Lybia (Text)", The New York Times, 23 de febrero de 2011. Disponible en: https://www.nytimes.com/2011/02/24/us/ politics/24obama-statement-libya.html.

PACKER, George, "Rights and Wrongs", The NewYorker, 17 de mayo de 2010. Disponible en: https://www.newyorker.com/magazine/2010/05/17/ rights-and-wrongs.

PACKER, George, "Witnessing the Obama Presidency, from Start to Finish", The New Yorker, 18 de junio de 2018. Disponible en: https: / / www.newyorker.com/magazine/2018/06/18/witnessing-the-obama-presidency-fromstart-to-finish.

PeredA, Cristina F., "Examen a las grandes promesas de Obama”, El País, 18 de agosto de 2016. Disponible en: https://elpais.com/internacio nal/2016/08/17/estados_unidos/1471396016_268432.html.

PISANI-FerRY, Jean, “Can Multilateralism Adapt?”, Bruegel, 3 de julio 2018. Disponible en: http://bruegel.org/2018/07/can-multilateralism-adapt/.

ReILly, Katie, "Read Barack Obama's Final Speech to the United Nations as President”, TIME, 20 de septiembre de 2016. Disponible en: http: / / time. com/4501910/president-obama-united-nations-speech-transcript/.

ReVESZ, Rachel, "Rex Tillerson Threatens to Withdraw from UN Human Rights Council to Improve Human Rights", The Independent, 15 de marzo de 2017. Disponible en: https://www.independent.co.uk/news/world/americas / rex-tillerson-un-human-rights-council-us-secretary-state-china-saudiarabia-egypt-a7630531.html.

RodríGueZ Huerta, Gabriela, México en el mundo. Constitución y política exterior, México, Fondo de Cultura Económica, 2017. 
Esta revista forma parte del acervo de la Biblioteca Jurídica Virtual del Instituto de Investigaciones Jurídicas de la UNAM

RosenberG, Eli y Morello, Carol, "U.S. Withdraws from UNESCO, the U.N.'s Cultural Organization, Citing Anti-Israel Bias”, TheWashington Post, 12 de octubre de 2017. Disponible en: https: / /www.washingtonpost.com/ news / post-nation / wp / 2017 / 10/12 /u-s-withdraws-from-unesco-the-u-n-scultural-organization-citing-anti-israel-bias/?utm_term $=.2 b 40986539 b 9$.

RugGIE, John Gerard, “Multilateralism: The Anatomy of an Institution”, International Organization, Massachusetts, vol. 46, núm. 3, 1992. Disponible en: https: //scholar.harvard.edu/files/john-ruggie/files/multilateralism.pdf.

RüHLE, Michael, "The Nuclear Weapons Ban Treaty: Reasons for Scepticism”, NATO Review, 19 de mayo de 2017. Disponible en: https://www. nato.int/docu/review/2017/also-in-2017/nuclear-weapons-ban-treaty-scepticism-abolition/en/index.htm.

Ruiz Cabañas IzQuierdo, Miguel y Rivera Chávez, María Paulina, "En defensa del multilateralismo", Revista Mexicana de Política Exterior, México, núm. 110, mayo-agosto de 2017. Disponible en: https://revistadigital.sre.gob. mx/images/stories/numeros/n110/ruizcabanasrivera.pdf.

SAUNDERS, Elizabeth N., "Is Trump a Normal Foreign-Policy President? What We Know After One Year", Foreign Affairs, 18 de enero de 2018. Disponible en: https://www.foreignaffairs.com/articles/united-states/2018-01-18/trump-normal-foreign-policy-president.

Sherman, Wendy, "How We Got the Iran Deal", Foreign Affairs, vol. 97, núm. 5, septiembre-octubre de 2018. Disponible en: https: / / www.foreignaffairs.com/articles/2018-08-13/how-we-got-iran-deal.

TARDIF, Eric, "Metamorfosis de la soberanía: elementos para una redefinición del concepto a la luz del derecho internacional contemporáneo”, Anuario de Derecho Constitucional Latinoamericano, Montevideo, año XVI, enero-diciembre de 2010. Disponible en: https://revistas-colaboracion. juridicas.unam. $m x$ /index.php / anuario-derecho-constitucional / article / view/3929/3452.

Thomson, Stéphanie, "4 Trends that Will Define the Future of US Foreign Policy", World Economic Forum, 26 de abril de 2016. Disponible en: https: / / www.weforum.org/agenda /2016/04/4-trends-that-will-define-thefuture-of-us-foreign-policy/.

Timm, Jane C., "The 141 Stances Donald Trump Took During his White House Bid", NBC News, 28 de noviembre de 2016. Disponible en: https: / / www.nbcnews.com / politics / 2016-election / full-list-donald-trump-srapidly-changing-policy-positions-n547801. 
Esta revista forma parte del acervo de la Biblioteca Jurídica Virtual del Instituto de Investigaciones Jurídicas de la UNAM

DOI: http://dx.doi.org/10.22201/iij.24487872e_2020.20_14491

Tudela, Fernando, “Trump y el Acuerdo de París”, Nexos, 1 de octubre de 2017. Disponible en: https: / /www.nexos.com.mx/?p=33948.

UN Watch, "This Year's UN Commission on Human Rights Structural Problems and Political Gamesmanship”, issue 25, 14 de abril de 1999. Disponible en: https: / /www.unwatch.org/issue-25-years-un-commission-human-rights-structural-problems-political-gamesmanship/.

Unger, David, "The Foreign Policy Legacy of Barack Obama”, The International Spectator, Bologna, vol. 51, núm. 4, 2016. Disponible en: http: / / www.iai.it/sites/default/files/unger.pdf.

Vabulas, Felicity, "Trump is Pulling the U.S. out of UNESCO. The Bigger Pattern is the Problem", TheWashington Post, 16 de octubre de 2017. Disponible en: https: / / www.washingtonpost.com/news/monkey-cage/wp/2017/ $10 / 16 /$ trump-is-pulling-the-u-s-out-of-unesco-the-bigger-pattern-is-theproblem/?noredirect $=$ on\&utm_term $=.84 c e 10 b f 52 a 5$.

Wright, Thomas, "Trump's 19th Century Foreign Policy", Politico Magazine, 20 de junio de 2016. Disponible en: https: / /www.politico.com/magazine/story/2016/01/donald-trump-foreign-policy-213546. 